\section{Case Reports in Neurology}

Case Rep Neurol 2020;12:299-306

DOI: 10.1159/000509287
Published online: September 18, 2020

(c) 2020 The Author(s)

Published by S. Karger AG, Basel www.karger.com/crn

This article is licensed under the Creative Commons Attribution-NonCommercial 4.0 International License (CC BY-NC) (http://www.karger.com/Services/OpenAccessLicense). Usage and distribution for commercial purposes requires written permission.

\title{
Effect of Flunarizine on Alternating Hemiplegia of Childhood in a Patient with the p.E815K Mutation in ATP1A3: A Case Report
}

\author{
Shouichirou Kusunoki Jun Kido Ken Momosaki Takaaki Sawada \\ Tomoko Kashiki Shirou Matsumoto Kimitoshi Nakamura \\ Department of Pediatrics, Graduate School of Medical Sciences, Kumamoto University, \\ Kumamoto, Japan
}

\section{Keywords}

Alternating hemiplegia of childhood $\cdot$ ATP1A3 $\cdot$ E815K $\cdot$ Flunarizine

\begin{abstract}
Alternating hemiplegia of childhood (AHC) (MIM 104290) is characterized by transient repeated attacks of paresis on either or both sides of the body, oculomotor and autonomic abnormalities, movement disorders, and cognitive impairment. Preventing paroxysmal attacks, such as paresis and spasm, in patients with AHC is often difficult. An 8-month-old girl presented to our institution with intractable epilepsy. She developed AHC, with left-right alternating or bilateral recurrent plegia upon waking, involuntary movements, eye movement abnormalities, and psychomotor retardation. She had a heterozygous de novo p.E815K mutation in the ATP1A3 gene. Patients with this mutation develop severe hemiplegic spells and convulsions, have a poor neuromotor developmental outcome, and are particularly difficult to treat. Flunarizine treatment has limited therapeutic effect in such patients; however, it was definitely effective for bulbar palsy in the present case. The present case further highlights the need for the development of other new treatments, such as a ketogenic diet.
\end{abstract}




\section{Case Reports in Neurology}

Case Rep Neurol 2020;12:299-306

DOI: 10.1159/000509287

(c) 2020 The Author(s). Published by S. Karger AG, Basel www.karger.com/crn

Kusunoki et al.: The Effect of Flunarizine in p.E815K Mutation in ATP1A3

\section{Introduction}

Alternating hemiplegia of childhood (AHC) (MIM 104290) is predominantly a sporadic disorder, with an incidence of 1 per 1,000,000 births, characterized by transient repeated attacks of paresis on either or both sides of the body, oculomotor and autonomic abnormalities, movement disorders, and cognitive impairment [1]. The paresis attacks exclusively occur during wakefulness and are completely relieved by sleep.

$A T P 1 A 3$, one of the causative genes of AHC, is a member of the gene family encoding the $\alpha$ subunits of $\mathrm{Na}^{+} / \mathrm{K}^{+}$-transporting ATPase, which regulates the electrochemical gradients of $\mathrm{Na}^{+}$and $\mathrm{K}^{+}$through active transport [2]. These ions are essential for the regulation of cellular osmolality and excitable membrane action potentials. ATP1A1, ATP1A2, and ATP1A3 genes encode the $\alpha 1,2$, and 3 subunits, respectively, and are mainly expressed in the cortex, hippocampus, basal ganglia, thalamus, cerebellum, and, to some extent, the heart [3].

The AHC phenotype is variable, and many pediatricians experience difficulties when treating patients with AHC. The main treatment objectives in AHC are the prevention of paroxysmal attacks, including paresis and spasms, which can be blocked by inducing sleep [4]. However, no therapy has been reported as definitely effective in preventing these attacks in patients with AHC.

We experienced a case of AHC in a female infant who developed left-right alternating or bilateral recurrent plegia upon waking, involuntary movements, eye movement abnormalities, and psychomotor retardation. She had a heterozygous de novo p.E815K mutation in the ATP1A3 gene. Herein, we present her clinical course and discuss the difficulties in treatment due to her genetic background.

\section{Case Report}

An 8-month-old girl presented to our institution with intractable epilepsy. She was the second child of healthy non-consanguineous parents. She was born at 38 weeks and 3 days of gestation and weighed 4,540 g. Her Apgar score was 8 at $1 \mathrm{~min}$ and 9 at $5 \mathrm{~min}$ after birth. Her mother had developed diabetes during pregnancy. The infant presented with prolonged hypoglycemia immediately after birth, sudden heart failure with lung bleeding at 3 days after birth, and neonatal jaundice at 6 days after birth. Moreover, she developed congenital bilateral hip dislocation. She presented with vertical and horizontal patterns of nystagmus starting at the age of 1 month; clonic spasms in the upper limbs, with facial flushing and lip cyanosis, at the age of 2 months; and right hemiplegia, persisting for 1 day after tonic spasms, at the age of 5 months. At the age of 6 months, the frequency of spasms increased to 2-3 times per week, despite receiving anti-seizure drugs, including phenobarbital (PB), sodium valproate (VPA), and levetiracetam (LEV). She acquired stable head control at the age of 5 months; at the age of 8 months, she could not maintain a seated position or roll over.

On admission, her height was $67.1 \mathrm{~cm}(-0.90$ standard deviation [SD]), weight was $7.4 \mathrm{~kg}$ $(-0.79 \mathrm{SD})$, and head circumference was $42.2 \mathrm{~cm}(-0.86 \mathrm{SD})$. She further developed weakness in the left upper and lower limbs and facial plegia on the left side. Her laboratory and cerebrospinal fluid tests did not reveal any significantly abnormal findings. At the age of 10 months, atherosis, chorea, and oral dyskinesia almost always presented upon waking, regardless of the presence of a plegic attack. Moreover, she developed paralytic attacks, which occurred within $20 \mathrm{~min}$ after waking and disappeared upon falling asleep, lasting for 24-48 h, every 2 weeks. She often received infusions and tube feedings because of poor oral intake. Her 


\section{Case Reports in Neurology}

Case Rep Neurol 2020;12:299-306

DOI: $10.1159 / 000509287$

(c) 2020 The Author(s). Published by S. Karger AG, Basel www.karger.com/crn

Kusunoki et al.: The Effect of Flunarizine in p.E815K Mutation in ATP1A3

electroencephalogram did not show any spikes during sleep, as well as on plegia during wakefulness. Magnetic resonance imaging (MRI) did not show any abnormal specific findings. However, single-photon emission computed tomography (SPECT) demonstrated reduced blood flow and a defect of accumulation of 123I-iomazenil in the bilateral frontal lobes (Fig. 1).

We suspected AHC because of the presence of left-right alternating or bilateral recurrent plegia upon waking; involuntary movements, including atherosis, chorea, and oral dyskinesia; eye movement abnormalities; and psychomotor retardation. Additionally, paradoxical movement, such that the vocal cord sometimes did not open during inspiration, was observed. Genetic analysis demonstrated a heterozygous p.E815K (c.2443G >A) mutation in the ATP1A3 gene (Fig. 2). Anti-seizure drugs, such as PB, VPA, LEV, topiramate (TPM), clonazepam (CZP), tazolamide (AZM), and gabapentin (GBP) were administered. However, it remains unclear which drugs were effective.

Involuntary movements always appeared during intermittent periods of paralysis upon waking. At the age of 1 year and 11 months, she started receiving flunarizine treatment (5 $\mathrm{mg} / \mathrm{kg} /$ day), which contributed to a decrease in the frequency of AHC symptoms, including limb weakness. In particular, this drug had positive effects on the pharyngeal muscle and muscles of respiration and could prevent cyanosis due to dysphagia. However, these symptoms deteriorated during a period in which she could not receive flunarizine because of enterogastritis and viral infection. Additionally, she continued to receive LEV (20 mg/kg/day) and GBP (20 mg/kg/day) as well as clobazam (CLB: $0.13 \mathrm{mg} / \mathrm{kg} /$ day) and lacosamide (LCM: 5.3 $\mathrm{mg} / \mathrm{kg} /$ day) for the treatment of partial seizures and localization-related epilepsy. Unilateral seizures appeared one to three times per month after receiving these anti-seizure drugs. The frequency of seizure attacks increased when the doses of these anti-seizure drugs were changed.

At the age of 5 years, she had reduced plegia and seizure attacks under the above antiseizure drugs and flunarizine. Although she could maintain an unstable seated position, she could not roll over because of an unbalanced body trunk with weakened muscles. Additionally, she developed severe mental retardation. Her development quotient on the Infant Analytical Development Enjoji Scale was 42 at the age of 5 years and 6 months.

\section{Discussion}

We present the case of a female infant with AHC who had a heterozygous de-novo p.E815K (c.2443G $>$ A) mutation in the ATP1A3 gene. This mutation has been detected in more than $75 \%$ of patients with AHC [5].

The type of mutation in AHC-related genes is correlated with the clinical severity of the disease, with an apparent dominant negative effect [6]. The p.D801N, p.E815K, and p.G947R mutations are the three most common mutations in the ATP1A3 gene [7, 8]. Several studies have reported that the p.E815K mutation has the most severe phenotype, with an earlier disease onset, higher frequency of status epilepticus, earlier onset of seizures, more frequent plegic attacks (typically of shorter duration), more severe cognitive and motor deficits, and more frequent autonomic dysfunction than that observed for other mutations [6, 9].

In contrast, the p.D801N mutation has a moderate phenotype. Patients with a p.D801N mutation first present with paroxysmal and hemiplegic symptoms at an older age, and have moderate cognitive impairment, with less frequent hemiplegic attacks. Additionally, the p.G947R mutation results in a milder type of AHC. Patients with the p.G947R mutation develop less frequent plegic episodes, with a tendency toward more frequent and longer dystonic 


\section{Case Reports in Neurology}

Case Rep Neurol 2020;12:299-306

DOI: $10.1159 / 000509287$

(c) 2020 The Author(s). Published by S. Karger AG, Basel www.karger.com/crn

Kusunoki et al.: The Effect of Flunarizine in p.E815K Mutation in ATP1A3

attacks, and have mild cognitive impairment. The age of seizure onset is earlier in patients with the p.G947R mutation than in patients with the D801N mutation [7].

Although the impact of p.E815K, p.D801N, and p.G947R mutations on $\mathrm{Na}+$ and $\mathrm{K}+$ transport is similar, proton transport is more significantly reduced by the p.E815K mutation than by the two other mutations $[6,10]$. The severity of the phenotype associated with the p.E815K mutation is considered to result from more profound intracellular alkalosis. As the intracellular proton concentration is known as an important modulator of neuronal excitability, increased intracellular alkalosis may certainly have severe consequences on neuronal function. Moreover, Japanese patients with the p.E815K mutation $[6,11,12]$ appear to be more severely affected than are patients in the United States AHC Foundation registry [8]. This suggests a possible influence of epigenetic or additional unknown genetic factors that modify the expression of the disease.

Many clinicians have administered various anti-seizure drugs to patients with AHC. However, anti-seizure drugs such as benzodiazepines have a limited effect on the spasm attacks, even though the enhancement of GABAergic input to pyramidal neurons is likely to depress excitability. ATP1A3 is mostly expressed in GABAergic neurons [3]; failure of one or more of the types of interneurons that inhibit pyramidal neurons causes an excitatory and inhibitory imbalance and may induce increased excitability with consequent seizures or an increased predisposition to spreading depression. Moreover, the dose of an anti-seizure drug should be slowly increased or decreased, as a sharp increase or decrease in the dose resulted in the exacerbation of seizures in the present case. The reason for this is unknown; however, a sharp increase or decrease in the dose of an anti-seizure drug may cause an excitatory and inhibitory imbalance in the pyramidal neurons.

Flunarizine, a non-selective calcium-channel blocker, is considered the most effective therapy for patients with AHC and it may reduce the frequency of hemiplegic attacks. The response to treatment with flunarizine ranges from $30 \%$ to $78 \%$, with a complete symptom response in only about $0-10 \%$ of patients with AHC [1]. Flunarizine treatment was definitely effective for bulbar palsy in the present case. Dysfunction or inactivation of the $\mathrm{Na}^{+}-\mathrm{K}^{+}$ATPase pump can cause the opening of $\mathrm{N}$-type voltage-gated calcium channels, leading to increased intracellular calcium. Moreover, pump dysfunction leads to increased intracellular $\mathrm{Ca}^{2+}$ concentration due to an activity loss or reversal of the $\mathrm{Na}^{+}-\mathrm{Ca}^{2+}$ exchanger, consequently inducing cell death or changes in gene expression. Additionally, an influx of calcium results in neuronal hyperexcitability. Therefore, flunarizine may exert beneficial effects by blocking voltage-gated $\mathrm{Na}^{+}$and $\mathrm{Ca}^{2+}$ currents, thereby limiting neuronal hyperexcitability and increasing the threshold against the development of cortical spreading depression. However, the reason flunarizine is effective in AHC, while other calcium-channel inhibitors are not effective, has not been definitely elucidated.

As observed in the present case, the discontinuation of flunarizine treatment is known to result in the exacerbation of hemiplegic episodes, as well as severe and catastrophic regression in motor function following hemiplegic spells and seizures, in some patients with the p.E815K mutation $[7,11,12]$. Helseth et al. [13] reported that the response to flunarizine injections in the p.E815K knock-in mouse model are consistent with the clinical results in humans, with an observed effect on the susceptibility and duration of the hemiplegic spells in response to stressors.

Recent reports have shown reduced disease activity in patients with AHC after receiving a ketogenic dietary treatment [14]. Thus, in the future, promising new treatments for AHC must be developed, which may include a ketogenic diet. 


\section{Case Reports in Neurology}

\begin{tabular}{l|l}
\hline Case Rep Neurol 2020;12:299-306 \\
\hline DOI: 10.1159/000509287 & $\begin{array}{l}\text { @ 2020 The Author(s). Published by S. Karger AG, Basel } \\
\text { www.karger.com/crn }\end{array}$ \\
\hline
\end{tabular}

Kusunoki et al.: The Effect of Flunarizine in p.E815K Mutation in ATP1A3

\section{Conclusions}

Patients with AHC who have the p.E815K mutation develop severe hemiplegic spells and convulsions, and their neuromotor developmental outcome is poor. Pediatricians experience significant difficulty in treating patients with AHC who have the p.E815K mutation. Various anti-seizure drugs, and even flunarizine treatment, have only limited therapeutic effects in such patients. Therefore, new effective treatments, such as a ketogenic diet, should be developed.

\section{Acknowledgements}

The authors thank the staff of the Kumamoto University Hospital Department of Pediatrics for their clinical contribution.

\section{Statement of Ethics}

The ATP1A3 gene analysis was approved by the ethical committee. Written informed consent for publication was obtained from the parents of the patient.

\section{Conflict of Interest Statement}

The authors have no conflicts of interest to disclose.

\section{Funding Sources}

This case report was supported, in part, by a Grant-in-Aid for Scientific Research from the Japanese Ministry of Education, Culture, Sports, Science, and Technology.

\section{Author Contributions}

Shouichirou Kusunoki and Jun Kido designed the case report and wrote the manuscript. Shouichirou Kusunoki, Jun Kido, Ken Momosaki, Takaaki Sawada, Kashiki Tomoko, and Shirou Matsumoto collected and analyzed the data. Jun Kido and Kimitoshi Nakamura supervised this case report and clinical practice. All authors read and approved the final manuscript.

\section{References}

1 Sweney MT, Silver K, Gerard-Blanluet M, Pedespan JM, Renault F, Arzimanoglou A, et al. Alternating hemiplegia of childhood: early characteristics and evolution of a neurodevelopmental syndrome. Pediatrics. 2009 Mar;123(3):e534-41.

2 Rosewich H, Thiele H, Ohlenbusch A, Maschke U, Altmüller J, Frommolt P, et al. Heterozygous de-novo mutations in ATP1A3 in patients with alternating hemiplegia of childhood: a whole-exome sequencing geneidentification study. Lancet Neurol. 2012 Sep;11(9):764-73. 


\section{Case Reports in Neurology}

\begin{tabular}{l|l}
\hline Case Rep Neurol 2020;12:299-306 \\
\hline DOI: 10.1159/000509287 & $\begin{array}{l}\text { @ 2020 The Author(s). Published by S. Karger AG, Basel } \\
\text { www.karger.com/crn }\end{array}$ \\
\hline
\end{tabular}

Kusunoki et al.: The Effect of Flunarizine in p.E815K Mutation in ATP1A3

3 Bøttger P, Tracz Z, Heuck A, Nissen P, Romero-Ramos M, Lykke-Hartmann K. Distribution of Na/K-ATPase alpha 3 isoform, a sodium-potassium P-type pump associated with rapid-onset of dystonia parkinsonism (RDP) in the adult mouse brain. J Comp Neurol. 2011 Feb;519(2):376-404.

4 Masoud M, Prange L, Wuchich J, Hunanyan A, Mikati MA. Diagnosis and Treatment of Alternating Hemiplegia of Childhood. Curr Treat Options Neurol. 2017 Feb;19(2):8.

5 Heinzen EL, Swoboda KJ, Hitomi Y, Gurrieri F, Nicole S, de Vries B, et al.; European Alternating Hemiplegia of Childhood (AHC) Genetics Consortium; Biobanca e Registro Clinico per l'Emiplegia Alternante (I.B.AHC) Consortium; European Network for Research on Alternating Hemiplegia (ENRAH) for Small and Mediumsized Enterpriese (SMEs) Consortium. De novo mutations in ATP1A3 cause alternating hemiplegia of childhood. Nat Genet. 2012 Sep;44(9):1030-4.

6 Li M, Jazayeri D, Corry B, McSweeney KM, Heinzen EL, Goldstein DB, et al. A functional correlate of severity in alternating hemiplegia of childhood. Neurobiol Dis. 2015 May;77:88-93.

7 Panagiotakaki E, De Grandis E, Stagnaro M, Heinzen EL, Fons C, Sisodiya S, et al.; Italian IBAHC Consortium; French AHC Consortium; International AHC Consortium. Clinical profile of patients with ATP1A3 mutations in Alternating Hemiplegia of Childhood-a study of 155 patients. Orphanet J Rare Dis. 2015 Sep;10(1):123.

8 Viollet L, Glusman G, Murphy KJ, Newcomb TM, Reyna SP, Sweney M, et al. Alternating hemiplegia of childhood: retrospective genetic study and genotype-phenotype correlations in 187 subjects from the US AHCF registry. PLoS One. 2015 May;10(5):e0127045.

9 Yang X, Gao H, Zhang J, Xu X, Liu X, Wu X, et al. ATP1A3 mutations and genotype-phenotype correlation of alternating hemiplegia of childhood in Chinese patients. PLoS One. 2014 May;9(5):e97274.

10 Vedovato N, Gadsby DC. Route, mechanism, and implications of proton import during $\mathrm{Na}+\mathrm{K}+$ exchange by native $\mathrm{Na}+$ /K+-ATPase pumps. J Gen Physiol. 2014 Apr;143(4):449-64.

11 Ishii A, Saito Y, Mitsui J, Ishiura H, Yoshimura J, Arai H, et al. Identification of ATP1A3 mutations by exome sequencing as the cause of alternating hemiplegia of childhood in Japanese patients. PLoS One. 2013;8(2):e56120.

12 Sasaki M, Ishii A, Saito Y, Morisada N, Iijima K, Takada S, et al. Genotype-phenotype correlations in alternating hemiplegia of childhood. Neurology. 2014 Feb;82(6):482-90.

13 Helseth AR, Hunanyan AS, Adil S, Linabarger M, Sachdev M, Abdelnour E, et al. Novel E815K knock-in mouse model of alternating hemiplegia of childhood. Neurobiol Dis. 2018 Nov;119:100-12.

14 Roubergue A, Philibert B, Gautier A, Kuster A, Markowicz K, Billette de Villemeur T, et al. Excellent response to a ketogenic diet in a patient with alternating hemiplegia of childhood. JIMD Rep. 2015;15:7-12. 


\section{Case Reports in Neurology}

\begin{tabular}{l|l}
\hline Case Rep Neurol 2020;12:299-306 \\
\hline DOI: 10.1159/000509287 & $\begin{array}{l}\text { (c) 2020 The Author(s). Published by S. Karger AG, Basel } \\
\text { www.karger.com/crn }\end{array}$ \\
\hline
\end{tabular}
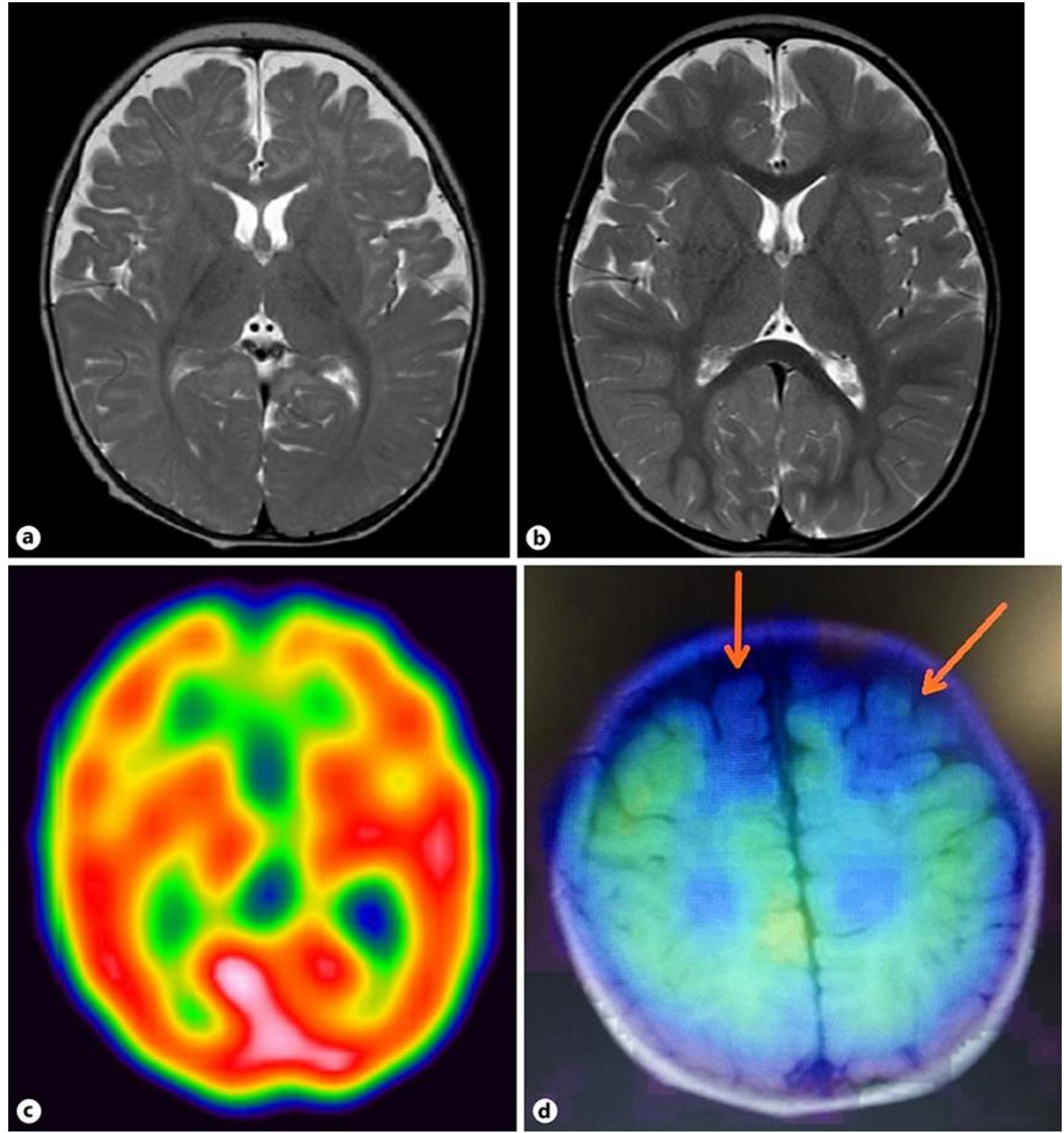

Fig. 1. MRI and SPECT images of the patient's brain. a T2-weighted image of the brain at the age of 4 months. b T2-weighted image of the brain at the age of 22 months. c. $99 \mathrm{mTc}$-ethyl cysteinate dimer SPECT image of the brain at the age of 11 months. d 123I-iomazenil SPECT image at the age of 11 months. The arrows indicate a defect of accumulation of 123I-iomazenil in the bilateral frontal lobes. MRI, magnetic resonance imaging; SPECT, single-photon emission computed tomography. 
Case Reports in Neurology
Case Rep Neurol 2020;12:299-306

DOI: $10.1159 / 000509287$

(c)

20 The Author(s). Published by S. Karger AG, Basel

Kusunoki et al.: The Effect of Flunarizine in p.E815K Mutation in ATP1A3

a
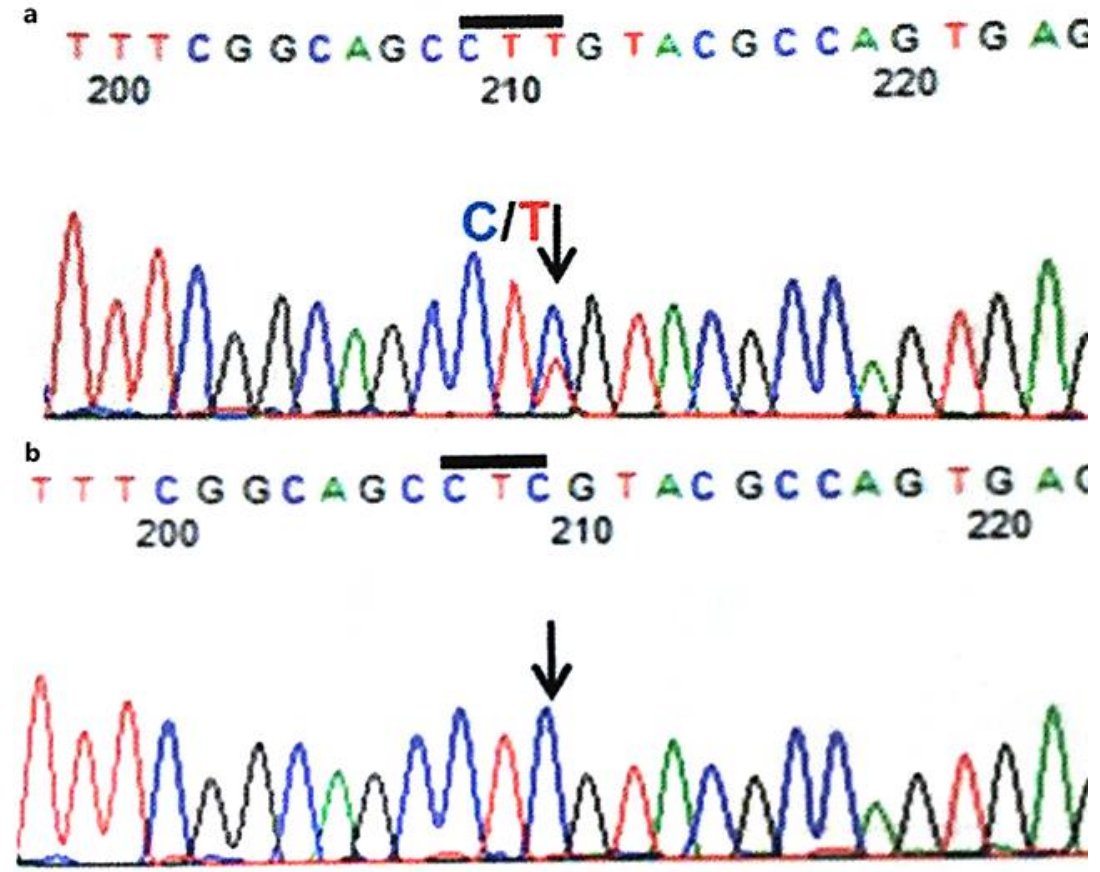

Fig. 2. The results of the sequence analysis of the $A T P 1 A 3$ gene. a The patient's (reverse) sequence. b Her mother's and father's (reverse) sequence. The arrows indicate the location of the mutation. 